\title{
Comparative study in prolapse lumbar intervertebral disc (PLID) surgery by spinal vs general anaesthesia
}

\author{
Md. Shahnewaz Chowdhury ${ }^{*}$, Sabya Sachi Roy ${ }^{2}$, Md. Matiur Rahman², Md. Mozaffer \\ Hossain $^{3}$, SMA Alim ${ }^{4}$ \\ ${ }^{*}$ Comilla Medical College, Comilla, ${ }^{2} \mathrm{M}$ A G Osmani Medical College, Sylhet. ${ }^{3}$ Dhaka Medical College Hospital, Dhaka, \\ ${ }^{4}$ Central Police Hospital, Dhaka. \\ *Corresponding author: snzchy@yahoo.com
}

\begin{abstract}
Background Lumbar discectomy is most commonly performed under general anaesthesia, which can be associated with several perioperative morbidities including nausea, vomiting, atelectasis, pulmonary aspiration, and prolonged post-anaesthesia recovery. It is possible that fewer complications may occur if the procedure is performed under spinal anesthesia.
\end{abstract}

Objective We have compared patient satisfaction between spinal versus general anaesthesia in patients for single level lumbar surgery.

Methods Eighty consecutive patients of ASA grade I-II were recruited and randomized into two equal groups, with half of this patients receiving spinal anaesthesia (n-40) and the remainder general anaesthesia (n-40). A comprehensive postoperative evaluation was carried out documenting any anaesthetic complications, pace of physiological and functional recovery and patient satisfaction. Variables were recorded as pain level using a visual analogue scale (VAS) at 1, 6, 12 and 24 hours; patient level of satisfaction during the stay on the ward using verbal rating scale (VRS) as it was detected by A p-value < 0.05 were considered as significant.

Results Spinal anaesthesia patients achieved the milestones of physiological and functional recovery more rapidly and reported less postoperative pain. Perioperative hypotension in $25 \%$ of patients and none was hypertensive in spinal group and in G/A Group 05\% of patients was hypotensive and $20 \%$ were hypertensive. Postoperative pain intensity more in G/A group than spinal group. Patient satisfaction in spinal group was more comparative to G/A group.

Conclusion Spinal anaesthesia ensures better operating conditions, better postoperative pain control and a quicker postoperative recovery when compared to general anaesthesia for single level lumbar spine surgery

Key words Prolapse lumbar intervertebral disc (PLID) surgery, spinal vs general anaesthesia.

(JBSA 2010; 23(2): 47-50)

\section{Introduction}

The surgical management of a prolapsed lumbar disc was first described by Mixter and Barr ${ }^{1}$ in 1934. Different anaesthetic techniques have been used for lumbar spinal surgery. In this study normally healthy and co-operative group of patients all study undergoing spinal surgery requiring less than 90 minutes of anaesthesia, the type of anaesthesia employed has traditionally been left to the individual preference of the Anaesthetist. Patients may favour general anaesthesia (GA) due to traditional considerations of being completely pain free during the surgery and also unaware of the procedure. Spinal anaesthesia (SA) for spinal surgery is becoming increasingly more popular because this anaesthetic technique allows the patient to self-position and avoid neurological injury that may occur with prone positioning under general anaesthesia. Spinal anaesthesia reduces intraoperative surgical blood loss, improves perioperative haemodynamic stability and reduces pain in the immediate postoperative period. ${ }^{2,3}$ This leads to a reduced need for analgesics and a reduction in the incidence of nausea and vomiting 
in the postoperative period. Spinal anaesthesia for lumbar spine surgery also decreases the incidence of lower extremity thrombo-embolic complications and does not increase the occurrence of problems with micturition. These benefits increase the patient's satisfaction, and they expedite discharge of the patient from the hospital ${ }^{4,5}$. Several studies have compared both anaesthetic techniques by measuring physiological variables. In our study we have compared patient satisfaction between spinal versus general anaesthesia in patients who underwent single level lumbar microdiscectomy. The aim of the study was to determine whether the mode of anaesthesia chosen for patients undergoing lumbar discectomy surgery has any significant influence on the immediate outcome in terms of postoperative pain, functional recovery and patient satisfaction.

\section{Methods}

Eighty healthy and co-operative patients ASA I-II undergoing Prolapse Lumbar Intervertebral Disc (PLID) surgery was included in the study from January 2008 to March 2010 at Sylhet M.A.G. Osmani Medical College Hospital \& private hospitals in Sylhet district, Bangladesh. All patients were given written informed consent to participate in the study and also for the procedure they were going to undertake. The exclusion criteria included history of severe cardiac disease, bleeding dyscrasias, infectious process, previous lumbar surgery and multilevel lumbar surgery. Patients were randomized to either the GA or SA group. Each specific mode of anaesthesia was standardised. Patients in the GA group were anaesthetised with Propofol $2.5 \mathrm{mg} / \mathrm{kg}$, fentanyl $2 \mathrm{mcg} / \mathrm{kg}$ and rocuronium $0.6 \mathrm{mg} / \mathrm{kg}$ to facilitate endotracheal intubation and mechanical ventilation. After achieving a general anaesthesia patients were then log rolled on to a prone position frame and special care was taken to protect the patient's arms, face, eyes and airway. ${ }^{6}$ General anaesthesia was maintained with the use of halothane $0.8 \%$ conveyed with a mixture of $40 \% \mathrm{O}_{2}\left(\mathrm{FiO}_{2}=0.4\right)$ and $\mathrm{N} 2 \mathrm{O} 60 \%$. Neuromuscular block was antagonised with neostigmine $0.4 \mathrm{mg} / \mathrm{kg}$ and atropine $0.02 \mathrm{mg} /$ $\mathrm{kg}$ at the end of the surgical procedure.

Patients in the SA group received their block in a sitting position with hyperflexion of the lumbar spine. After the lower back was prepared and draped, the skin was infiltrated with $2-3 \mathrm{ml}$ of $1 \%$ Lignocaine. Then a $25 \mathrm{G}$ Quinkee spinal needle was introduced one or two levels above the herniated disc. 2.5 to $2.8 \mathrm{ml}$ of $0.5 \%$ Bupivacaine Heavyt + inj. fentanyl $12.5 \mathrm{mg}$ was injected into the subarachnoid space. Patients were returned to the supine position and log rolled to the prone position frame once a stable spinal level was achieved. In both groups, Hartmann's solution $(5 \mathrm{ml} / \mathrm{kg})$ was administered and when systolic B.P. below $90 \mathrm{mmHg}$ was treated with an intravenous injection of Ephedrine (3mg). At the end of the surgical procedure, the patient was rolled to a supine position on a bed and transferred to the recovery room. Postoperative analgesia was administered in the form of Injection pethedine 2 $\mathrm{mg} / \mathrm{kg}$ intramuscularly in both group of patient stat and 6 (six) hourly.

Comprehensive postoperative evaluation concentrated on documenting any complications specific to the particular mode of anaesthesia, recording the pace at which the various milestones of physiological and functional recovery were reached and the level of patient satisfaction with the type of anaesthesia used. The following variables were recorded: pain integrity was detected using a visual analogue scale (VAS) at 1,6, 12 and 24 hours; using a scale, verbal rating scale (VRS).as in : Excellent, Good, Fair, Poor .

\section{Results}

In this study demographic characteristics did not differ between the two groups (Table-I). The distribution of men and women in both SA and GA groups was comparable as well as the distribution in relation to the level of surgery. No serious complication specific to their particular mode of anaesthesia occurred in either group (Table II\&III). Significance of difference between Spinal and G/A group in postoperative pain relief by VAS estimated after 1, 6, 12, 24, hours (Table IV). Level of comfort after surgery by VRS (verbal rating score) was better in spinal group comparative to G/A group (Table-V). Time of total duration of Surgery showed highly significant value in spinal group than G/A Group (Table VI). 
TableI Demographic characteristics of patients

\begin{tabular}{lccc}
\hline Group & $\begin{array}{c}\text { Age (mean) } \\
\text { in Years }\end{array}$ & $\begin{array}{c}\text { Sex } \\
(\mathrm{M}:: \mathrm{F})\end{array}$ & $\begin{array}{c}\text { Body Weight } \\
\text { (mean) kg }\end{array}$ \\
\hline Spinal (n-40) & $41.10 \pm 1.18$ & $51: 29$ & $57.20 \pm 1.77$ \\
G/A (n-40) & $42.80 \pm 1.59$ & $47: 33$ & $56.80 \pm 2.36$ \\
\hline
\end{tabular}

Statistical analysis was done by student's 't' test

$P$ value $<0.05$ significant

TableII Complication spinal vs General Anaesthesia

\begin{tabular}{lcc}
\hline Complication & $\begin{array}{c}\text { Spinal } \\
\text { Group }\end{array}$ & $\begin{array}{c}\text { General Anaesthesia } \\
\text { Group }\end{array}$ \\
\hline Hypotension & $10(25 \%)$ & $02(05 \%)$ \\
Hypertension & $00(00 \%)$ & $08(20 \%)$ \\
Tachycardia & $15(37.5 \%)$ & $26(27.5 \%)$ \\
Bradycardia & $12(30 \%)$ & $02(05 \%)$ \\
Vomiting /Nausea & $05(12.5 \%)$ & $00(0 \%)$ \\
Shivering & $04(10 \%)$ & $00(0 \%)$ \\
\hline
\end{tabular}

Table III Postoperative Complication

\begin{tabular}{llc}
\hline Complication & $\begin{array}{c}\text { Spinal } \\
\text { Group }\end{array}$ & $\begin{array}{c}\text { General Anaesthesia } \\
\text { Group }\end{array}$ \\
\hline Hypotension & $02(05 \%)$ & $00(0 \%)$ \\
Hypertension & $03(7.5 \%)$ & $12(27.5 \%)$ \\
Tachycardia & $11(26.25 \%)$ & $18(44 \%)$ \\
Bradycardia & $08(19 \%)$ & $04(9.5 \%)$ \\
Vomiting /Nausia & $02(05 \%)$ & $08(19 \%)$ \\
Shivering & $02(05 \%)$ & $03(7.5 \%)$ \\
Urinary Retention & $08(19 \%)$ & $04(9.5 \%)$ \\
\hline
\end{tabular}

Table IV Assessment of postoperative pain relief by VAS score ( $\mathrm{mm}$ ) estimated after 1, 6,12,24, hours

\begin{tabular}{lccc}
\hline Time period & Spinal Group & G/ A Group & P-value \\
\hline After 01 hrs & $28.5 \pm 9.6$ & $38.1 \pm 11.3$ & $<0.001$ \\
After 6 hrs & $37.8 \pm 11.5$ & $45.2 \pm 6.5$ & $<0.05$ \\
After 12 hrs & $33.3 \pm 7.6$ & $40.3 \pm 8.7$ & $<0.01$ \\
After 24 hrs & $31.4 \pm 9.6$ & $38.3 \pm 9.2$ & $<0.01$ \\
\hline
\end{tabular}

Mean \pm SEM $\mathrm{P}<0.05$ significant
Table V Levels of comfort after surgery. by VRS (verbal rating score)

\begin{tabular}{lcc}
\hline Comfort & Spinal Group & G/A Group \\
\hline Excellent & $45 \%$ & $27 \%$ \\
Good & $40 \%$ & $48 \%$ \\
Fair & $15 \%$ & $23 \%$ \\
Poor & $00 \%$ & $02 \%$ \\
\hline
\end{tabular}

Table VI Duration of Surgery:

\begin{tabular}{lccc}
\hline Time & Spinal Group & G/A Group & P value \\
\hline Time of total & $74.06 \mathrm{~min}$. & $85.05 \mathrm{~min}$. & $<0.001$ \\
duration of & & & \\
Surgery & & & \\
\hline
\end{tabular}

Statistical analysis was done by student's 't' test, Value are expressed p. $\mathrm{p}<.015$ significant $(* *)$

\section{Discussion}

General and spinal anaesthesia are both used for lumbar spine surgery. As previous studies have suggested, SA seems to be superior to GA in terms of postoperative pain and in decreasing perioperative undesirable results. However, no studies in the English literature have compared patient satisfaction evaluating functional recovery variables. ${ }^{1,7}$. A previous study by Dagher et $a l^{2}$ shows similar results with SA patients performing better from the functional recovery point of view and scoring better pain level. The only other recent reports involving large numbers of patients are from Jellish et al. ${ }^{3}$ in the USA. In our study SA has demonstrated to be superior to GA from the patient's satisfaction point of view. Pain level reported by GA patients was always higher than SA patients and the difference was especially significant at 8 hours. Similarly there are significant differences in the level of comfort, SA patients reporting a better level of comfort in general, similar studies reported by J. Perez Rodriguez et $a l^{4}$. Pethidine was used as postoperative analgesia. According VAS Score GA group reported a higher level of pain with similar significance at 1, 6, 12 and 24 hours. There is no significant difference between gender and level of pain. Direct relation between the age of the patient and the level of pain was found, especially in the SA group, with a higher level of pain in older patients ${ }^{8}$. Spinal anaesthetic patients reported a less incidence of urinary retention, which differs with previous 
studies where both anaesthetic techniques have been compared ${ }^{5,7}$. Blinded to an extent by not having experienced the alternative, both groups appeared satisfied with their anaesthetic. However the level of satisfaction was significantly higher in the SA group. Spinal anaesthesia ensures better operating conditions, better postoperative pain control and a quicker postoperative recovery when compared to general anaesthesia for single level lumbar spine surgery. Spinal anesthesia was as safe and effective as general anaesthesia for patients undergoing lumbar laminectomy. Potential advantages of spinal anaesthesia include a shorter anaesthesia duration, decreased nausea, antiemetic and analgesic requirements, and fewer complications.

\section{References}

1. Mixter WJ, Barr JS: Rupture of the intervertebral disc with involvement of the spinal canal. N Engl J Med. 1934; 211:210-215

2. Dagher C, Naccache N, Narchi P, Hage P, Antakly MC. Anesthesia locoregionale pour cure microchirurgicale des hernies discales lombaires. Journal Medical Libanais. 2002; 50:206-210
3. Jellish WS, Thalji Z, Stevenson K. A prospective randomised study comparing short and intermediate term perioperative outcome variables after spinal or general anesthesia for lumbar disk and laminectomy surgery. Anesthesia and Analgesia 1996; 83: 559-64

4. Rodriguez JP, Tambe A, Dua R, Pereda E, Calthorpe D . Spinal or General anaesthesia for lumbar spine microdiscectomy Surgery does it matter? . The Internet Journal of Spine Surgery 2007; 2

5. Hudgins RW. The role of microdiscectomy. Orthop Clin North Am 1983; 14:589-603.

6. Moore DC, Edmonds LH: Prone position frame. Surgery 1950; 27:276-9

7. Mahan KT. Wang J. Spinal morphine anaesthesia and urinary retention. J Am Podiatr Med Assoc 1993; 83:607-14

8. Scott Jellish W, Thalji Z, Stevenson K, Shea J. A prospective randomized study comparing short-and intermediate-term perioperative outcome variables after spinal or general anaesthesia for lumbar disk and laminectomy surgery. Anaesth Analg 1996; 83:559-64 